\section{INFÂNCIA E DIREITOS: O USO DE METODOLOGIAS PARTICIPATIVAS EM CONTEXTO DE ACOLHIMENTO INSTITUCIONAL}

\author{
Childhood and Rights: The Use of Participation Methodology \\ in the Context of Institutional Care
}

\author{
Infancia y Derechos: La Utilización de Metodologías \\ Participativas en el Contexto de Acogida Institucional
}
Enfance et Droits: L'utilisation de Méthodes Participatives en Contexte D'accueil Institutionnel

\begin{abstract}
Resumo
A temática dos direitos das crianças tem ganhado cada vez mais destaque nas últimas décadas, principalmente após a aprovação da Convenção dos Direitos da Criança da Organização das Nações Unidas (ONU) e promulgação do Estatuto da Criança e do Adolescente (ECA) no Brasil. Neste estatuto, as crianças são concebidas como sujeitos de direitos e não como "menores", como vigorava na legislação brasileira anterior. No âmbito dos direitos, percebese que o mais recentemente discutido é o direito de participação e isso inclui a valorização e a defesa da participação infantil na realização de pesquisas com crianças. Desta forma, o objetivo desta pesquisa é analisar a influência da situação de acolhimento institucional sobre a forma como as crianças se percebem e se posicionam como sujeito de direitos. Participaram 14 crianças de 8 a 12 anos em situação de acolhimento institucional. Os dados foram coletados através de metodologias participativas, buscando dar espaço aos participantes de se colocarem sobre o que sabem e percebem como direitos das crianças e quais deles lhe são garantidos ou violados. Os resultados mostraram que as crianças possuem amplo conhecimento sobre situações de violação de direitos, o que pode ilustrar a falta de garantia dos mesmos em seu cotidiano. Entretanto, elas não apresentam conhecimentos sobre seus direitos e nem a que pessoas ou instituições poderiam recorrer para que seus direitos deixassem de ser violados. Conclui-se que o contexto de acolhimento institucional contribui de forma significativa para a formação da concepção de direitos das crianças, ficando evidente a necessidade de uma maior divulgação e efetivação dos direitos previstos no ECA nos mais diferentes contextos, especificamente no de acolhimento institucional. Além disso, a partir da pesquisa foi possível verificar a adequação das metodologias participativas como forma privilegiada de acessar as crianças e suas percepções acerca de aspectos importantes sobre seus modos de vida.
\end{abstract}

Palavras-chave: acolhimento institucional; direitos; metodologias participativas; crianças; participação.

\begin{abstract}
The theme of children's rights has gained increasing in the last decades, especially after the adoption of the Statute of the Child and Adolescent (ECA) in Brazil. In this statute, children are conceived as subjects of rights and not as "minors", as it existed earlier in the Brazilian legislation. When it comes to children's rights, the most recently debated is the right of participation and that includes appreciation and defense of children's participation in researches with children. Thus, the objective of this research is to analyze the influence of care institutions'situation on how children perceive and position themselves as subjects of rights. In this investigation 14 children with 8-12 years in situation of foster care institution participated. The data were collected through participation methodologies, aiming to give space to the participants to tell about what they know and perceive as children's rights and which ones are guaranteed or violated for them. The results showed that these children
\end{abstract}

Artigo Original

Juliana Prates Santana ${ }^{(1)}$ Janaina Rocha Avanzo (2)

1) Professora Adjunto da Universidade Federal da Bahia, Mestre em Psicologia do Desenvolvimento pela Universidade Federal do Rio Grande do Sul, e Doutora em Estudos da Criança pela Universidade do Minho, Braga, Portugal.

2) Graduada em Psicologia na Universidade Federal da Bahia, bolsista do Programa de Iniciação Científica (PIBIC/ UFBA).
Recebido em: 14/12/2013 Revisado em: 19/06/2014 Aceito em: 19/11/2014 
possess great knowledge about situations of rights'violations, which can illustrate the lack of assurance of these rights in their everyday lives. However, they do not have general knowledge about their rights or the people or institutions they could look for to stop their rights from being violated. In conclusion, the foster care context contributes in a significant manner to constituting children's conception of their rights, and it becomes necessary to further the dissemination and application of the rights described in ECA in many different contexts, including the foster care institutions. Besides, from this research, it was possible to verify the adequacy of participation methodologies as a privileged way of accessing children and their perception of important aspects of their lives.

Keywords: care institutions; rights; participation methodologies; children; participation.

\section{Resumen}

El tema de los derechos de los niños ha adquirido cada vez mayor importancia en las últimas décadas, sobre todo después de la aprobación de la Convención de los Derechos del Niño de las Naciones Unidas y promulgación del Estatuto del Niño y del Adolescente (ECA) en Brasil. En este estatuto, los niños son concebidos como sujetos de derechos y no como "menores", como eran considerados anteriormente en la legislación brasileña. En el campo de los derechos, se observa, en los últimos años, un debate sobre el derecho a la participación, lo que incluye la valoración y la defensa de la participación infantil en la realización de investigaciones sobre los niños. Por lo tanto, el objetivo de esta investigación es analizar la influencia de la situación de la acogida institucional sobre cómo los niños perciben a si mismos y se posicionan como sujetos de derechos. Participaron en esta investigación 14 niños de 8-12 años en la situación de la acogida institucional. Los datos fueron recolectados a través de metodologías participativas, tratando de dar espacio a los participantes a posicionarse sobre lo que saben y perciben como los derechos de los niños y cuáles están asegurados o violados en sus vidas Los resultados mostraron que los niños poseen un gran conocimiento sobre las situaciones de violación de derechos humanos, lo que puede ilustrar la falta de garantía de estos en su vida cotidiana. Sin embargo, ellos no tienen conocimiento de sus derechos en general y de las personas o instituciones que podrian utilizar para que sus derechos ya no sean violados. Se concluye que el contexto de acogida institucional contribuye de forma significativa para la formación de la concepción de derechos de los niños, evidenciando la necesidad de una mayor difusión y aplicación de los derechos previstos en el ECA en muchos contextos diferentes, incluyendo en contexto de acogida institucional. La investigación también demostró la adecuación de las metodologías participativas como forma privilegiada de acceso a los niños y sus percepciones sobre aspectos importantes de sus modos de vida.

Palabras clave: acogida institucional; derechos; metodologías participativas; niños; participación.

\section{Résumé}

La thématique des droits de l'enfant a connu une visibilité accrue dans les dernières decénies, surtout après l'approbation de la
Convention des Droits de l'Enfant (ONU) et la promulgation du Statut de l'Enfant et de l'Adolescent (ECA) au Brésil. Dans ce dernier, les enfants sont perçus comme des sujets de droit et non des «mineurs», comme c'était le cas dans la législation brésilienne précédente. En ce qui concerne les droits, on remarque que celui qui a été le plus discuté récemment est celui de participation, et cela inclut la valorisation et la défense de la participation de l'enfant dans la réalisation de recherches avec celui-ci. Ainsi, l'objectif de la présente recherche est d'analyser l'influence de la situation d'accueil institutionnel sur la manière dont les enfants se perçoivent et se positionnent comme sujets de droit. 14 enfants entre 8 et 12 ans en situation d'accueil institutionnel $y$ ont participé. Les données ont été collectées au moyen de méthodes participatives, en permettant aux participants de s'exprimer sur ce qu'ils comprenaient comme droits de l'enfant et de désigner lesquels leur étaient garantis ou violés. Les résultats ont montré que les enfants avaient une ample connaissance sur les situations de violation de droits, ce qui pourrait illustrer le manque de garantie de ceux-ci dans leur quotidien. Toutefois, elles ne montraient pas de connaissances sur leurs droits et sur les personnes ou institutions à qui s'adresser pour que ceux-ci cessent d'être violés. On en conclut que le contexte d'accueil institutionnel contribue de manière siginificative à la formation de la conception des droits chez les enfants, en soulignant la nécessité d'une plus grande divulgation et effectivation des droits prévus dans l'ECA dans les contextes les plus divers, spécifiquement dans celui d'accueil institutionnel. De plus, à partir de la recherche, il a été possible de vérifier l'adéquation des méthodes participatives comme moyens privilégiés d'avoir accès aux enfants et à leur perception au sujet des aspects importants de leurs modes de vie..

Mots-clés: accueil institutionnel; droits; méthodes participatives; enfants; participation.

A temática dos direitos das crianças tem ganhado cada vez mais destaque nas últimas décadas, principalmente após a ratificação da Convenção dos Direitos da Criança (CDC, 1989) e, no caso brasileiro, da aprovação do Estatuto da Criança e do Adolescente (ECA, Lei no 8.069/90, 1990), eliciando debates tanto no meio científico quanto em outros âmbitos da sociedade. Entretanto, ainda não se sabe até que ponto esse conhecimento chegou às próprias crianças, pois a divulgação e discussão sobre esses direitos não implicou, necessariamente, na superação da violação dos mesmos, nem na diminuição das desigualdades vivenciadas pelas crianças, já que muitas ainda se encontram em situação de vulnerabilidade social.

O ECA concebe as crianças como sujeitos de direitos e não como "menores", como vigorava na legislação brasileira anterior. Dessa forma, a criança deixa de ser propriedade da família e passa a ser prioridade do Estado, já que são sujeitos de direitos em situação peculiar de desenvolvimento. Neste sentido, a criança se torna responsabilidade de todos, não 
só do Estado, mas também da família e, principalmente, da sociedade, prover e defender os direitos das crianças.

Esses direitos são divididos em: direitos de provisão, de proteção e de participação (Fernandes, 2009), não havendo uma hierarquia entre os mesmos, ou seja, teoricamente não haveriam direitos que deveriam ser garantidos prioritariamente a outros na garantia integral da criança. Os direitos de provisão estão relacionados ao acesso que as crianças podem e devem ter à educação, saúde, segurança social, vida familiar, cultura, lazer e cuidados físicos. Já os direitos de proteção se baseiam em uma atenção distinta que deve ser dada às crianças, por estarem mais expostas às situações de vulnerabilidade social e, consequentemente, à violação de seus direitos. Por fim, os direitos de participação estão relacionados à ideia da criança como um sujeito ativo em seu próprio desenvolvimento e, por isso, têm acesso a direitos civis e políticos, ou seja, a criança tem liberdade de expressão e opinião, deve ser consultada e ouvida, pode ter acesso à informação e tem o direito de tomar decisões. De acordo com Sarmento e Pinto (1997), o reconhecimento desses direitos não garante o seu cumprimento, havendo um avanço desigual na defesa dos mesmos, sendo que o direito de participação foi o que menos avançou a nível mundial.

A participação infantil também tem sido valorizada e defendida no âmbito das pesquisas com crianças. Entretanto, poucos são os estudos que buscam saber a perspectiva das crianças sobre seus direitos, especialmente aqueles que levam em consideração metodologias que aumentem a possibilidade da criança participar de forma adequada. Nem sempre as metodologias tradicionais conseguem captar as ideias da criança ou possibilitar sua expressão, por conta do excesso de poder geracional exercido (Fernandes, 2009).

A análise de algumas produções na área de investigação sobre os direitos das crianças na perspectiva das mesmas, permite perceber que os estudos tendem a utilizar metodologias tradicionais de investigação. Na pesquisa realizada por Ruck, Keating, Abramovitch e Koegl (1998) foi utilizada uma entrevista semiestruturada que objetivava investigar o que as crianças sabiam sobre os seus direitos. Participaram do estudo 169 crianças e adolescentes de 8 a 16 anos em Toronto, de maioria branca, mas distribuídas nas diferentes classes sociais, e selecionadas em escolas da área metropolitana da cidade. Grande parte dos participantes, mesmo os adolescentes mais velhos, colocou os direitos mais como algo concreto, do que se pode e se quer fazer, do que como algo abstrato, como encontrado em outros estudos. Apresentaram ainda uma forte crença de que esses direitos podem ser retirados por uma autoridade, apesar de, a partir dos 10 anos, as crianças já terem certa noção de que existem direitos que são próprios dos seres humanos por natureza, que não podem ser retirados. As crianças deste estudo também falaram mais sobre direitos relacionados à autonomia do que os direitos mais naturais, como proteção e provisão. Um dos pontos importantes colocados por esses autores é que se faz necessário um cuidado na pesquisa com crianças sobre direitos para saber o que elas realmente pensam sobre este tema, já que é um tema que sofre muita influência social e cognitiva. A importância de uma entrevista semiestruturada é identificado como algo inovador do estudo, que está relacionado a saber o que a criança pensa sobre direito de forma mais espontânea.

Um estudo feito por Haydon (2008) e promovido pela Northern Ireland Commissioner for Children and Young People (NICCY) buscou investigar como as crianças entendiam, percebiam e avaliavam seus direitos. Os 132 participantes de 8 a 24 anos e de diferentes grupos sociais (incluindo crianças e adolescentes com necessidades especiais, LGBT, de minorias étnicas, entre outras) trouxeram como direitos necessários às crianças: água, comida, abrigo, serem ouvidas, serem tratadas com respeito e igualmente, se envolverem em decisões, poderem praticar sua própria religião, estarem protegidas de danos, terem acesso à saúde e à educação, terem lugares seguros e diferenciados para brincar, entre outros. Os participantes também colocaram questões como o fato das pessoas consideraram as crianças apenas como futuros adultos, algo que deve ser modificado juntamente com o aumento da capacidade de ouvir mais as crianças. Outro ponto colocado pela autora é que as crianças possuem um entendimento intuitivo de que possuem direitos, mas isso não acontece por causa da Convenção dos Direitos das Crianças (United Nations Convention on the Rights of the Child), que não alcança as crianças nem para lhes facilitar o conhecimento de seus direitos nem para intervir em suas vivências diárias de garantia e descumprimento dos mesmos.

Veiga (2001) pesquisou com 294 crianças de 7 a 9 anos, estudantes em diferentes escolas (rurais, de pequenas cidades, suburbanas e de grandes cidades) de Portugal, a percepção que elas têm em relação aos direitos, utilizando a Children's Rights Scale, que é dividida em respostas sobre direitos importantes na escola, exercidos na escola, importantes em casa ou exercidos em casa. O autor encontrou que as crianças sabem que seus direitos se dão tanto na escola como em casa, mas que os direitos em geral são mais importantes do que exercidos. O professor apareceu como um promotor de direitos e conhecimento sobre os mesmos para as crianças. Não houve diferenças nas respostas de meninos e meninas, mas sim nas respostas das crianças de diferentes escolas e, consequentemente, de diferentes classes sociais, pois as crianças que apresentavam problemas na escola ou famílias que não valorizavam os direitos não os consideraram tão importantes e exercidos quanto as outras crianças, o que demonstra a importância do contexto para a concepção e vivencia das crianças no que se 
refere ao exercício dos seus direitos.

Já Fernandes (2009) realizou um estudo baseado em metodologias participativas com crianças de 8 a 13 anos, algumas delas de uma escola pública de classe média e outras de um abrigo em Portugal. O uso das metodologias citadas se mostrou importante para colocar os participantes como ativos e ouvidos no processo de pesquisa. As crianças da escola mostraram um maior conhecimento em relação com os direitos do que aquelas do abrigo, o que mostra, mais uma vez, a importância do contexto para entender a concepção das crianças sobre direitos.

Souza (2008) pesquisou o conhecimento e a percepção de direitos de adolescentes de 12 a 17 anos habitantes da região metropolitana de Porto Alegre, através de um Inventário de Autorrelato sobre Direitos de Adolescentes. Os participantes foram de três grupos diferentes: adolescentes em situação de acolhimento institucional; estudantes de escola pública e; estudantes de escola particular. Os resultados apontaram que, de modo geral, os adolescentes têm ciência dos seus direitos, mas um conhecimento mais profundo depende do direito analisado. Muitos participantes atribuíram condições (financeiras, morais, comportamentais) para que os direitos sejam garantidos.

Outra pesquisa realizada em âmbito nacional por Santos e Chaves (2010) procurou investigar o reconhecimento de direitos e de significados de infância relacionados a esses direitos. Os participantes foram crianças de 9 a 11 anos da cidade de Senhor do Bonfim, na Bahia, divididas em três grupos: estudantes de escola particular urbana, estudantes de escola pública urbana e estudantes de escola pública rural. As crianças responderam a uma entrevista semiestruturada estimulada pela apresentação de imagens representando cenas protagonizadas por crianças. Nos resultados, foi possível perceber que as crianças mostraram maior conhecimento sobre direitos de alimentação, educação e brincar, mas apresentam ideias diferenciadas em cada contexto sobre a proibição do trabalho e o direito inviolabilidade da integridade física.

Desta forma, é necessário levar em consideração o contexto em que a criança se encontra para entender a concepção que ela tem sobre direitos. Não apenas o país, a situação socioeconômica, mas também a exposição a vulnerabilidades que podem aumentar a violação de seus direitos e também a possibilidade de participação que cada uma delas possui. Um dos contextos que podem ter grande influência na garantia dos direitos das crianças e na percepção que elas terão dos mesmos é o contexto de acolhimento institucional.

A pesquisa da concepção de direitos de crianças em situação de acolhimento institucional se faz importante porque vai muito além do que elas dizem sobre os direitos.
É preciso atentar à vivência que as crianças têm dentro dos abrigos, considerando que, nesses locais, elas têm diversos dos seus direitos garantidos e violados ao mesmo tempo. Entender como as crianças percebem suas vidas nos abrigos é entender como elas percebem seus direitos e os direitos das crianças em geral.

Além disso, se fazem necessárias mais pesquisas que valorizem as vozes das crianças, na medida em que conhecer o contexto de acolhimento institucional e os direitos das crianças pela perspectiva das mesmas, além de útil, é essencial para se entender de forma completa estes espaços e a aplicação prática do Estatuto da Criança do Adolescente. Por outro lado, investigar as concepções e direitos das próprias crianças abrigadas pode servir de subsídio para o aprimoramento de políticas voltadas ao direito das crianças e da política de acolhimento, que, apesar de ser de caráter excepcional, atende a um número expressivo de crianças.

Portanto, o objetivo desta pesquisa é analisar a influência da situação de acolhimento institucional sobre a forma como crianças se percebem e se posicionam como sujeito de direitos. Assim, é preciso identificar as concepções de direitos de crianças em situação de acolhimento institucional, compreender em que medida e em que situações essas crianças se percebem como sujeito de direitos, investigar como as crianças inseridas nas unidades de acolhimento institucional se posicionam diante de situações que percebem como situações de respeito ou de violação de seus direitos e contribuir para a compreensão dos aspectos inerentes ao contexto de acolhimento que influenciam (positiva ou negativamente) no exercício dos direitos das crianças.

Primeiramente será apresentado um panorama geral do acolhimento institucional e pesquisas realizadas neste contexto com as crianças, visando compreender as especificidades deste meio social e as caraterísticas que podem favorecer ou dificultar a vivência concreta de direitos por parte das crianças. Em seguida, serão apresentadas as estratégias metodológicas adotadas no estudo, enfatizando as particularidades da pesquisa participativa com crianças. Os resultados e análise dos mesmos serão acompanhados das considerações finais e impactos que este estudo pode ter para a compreensão da concepção de direitos das crianças.

\section{Acolhimento Institucional}

A unidade de acolhimento institucional é caracterizada por ser um espaço de proteção provisório e excepcional para crianças e adolescentes que não possam ficar com suas famílias por conta de violação de direitos ou de riscos pessoais e sociais (Centro de Apoio Operacional da Infância, Juventude e Educação, 2009). Trata-se de uma medida que deve ser adotada em situações excepcionais, quando todas 
as medidas de proteção previstas em lei já foram adotadas e não obtiveram êxito na garantia do direito das crianças.

De acordo com a legislação vigente, as unidades de acolhimento institucional devem possibilitar um contexto similar àquele oferecido no convívio familiar, funcionando em unidades pequenas, com atendimento personalizado, preservando-se grupos de irmãos e garantindo as visitas de familiares e também a participação comunitária da criança. Destaca-se que o acolhimento institucional deve ser provisório, com duração máxima de 2 anos, e este tempo deve ser utilizado primordialmente para se refazer os vínculos familiares, de modo que a criança retorne à família biológica sem continuar na situação de vulnerabilidade que se encontrava antes de ir para o acolhimento. Caso o retorno à família não seja possível, há uma supressão do poder familiar sobre a criança e esta aguardará na unidade de acolhimento institucional por uma adoção (Governo Federal, 1990).

Devido a diversas dificuldades encontradas na aplicação do ECA em relação às instituições de acolhimento, novos documentos são criados para orientar funcionários dos abrigos e todos os profissionais envolvidos na situação de acolhimento institucional para que esta se torne adequado para a criança. Um desses documentos, Orientações Técnicas para Serviços de Acolhimento para Crianças e Adolescentes (CNAS \& CONANDA, 2009), estabelece as orientações metodológicas e os parâmetros para o funcionamento dos abrigos. Outro documento é a Lei 12.010 (2009) que traz modificações nas práticas de acolhimento institucional, como a reavaliação da situação da criança a cada 6 meses no máximo, a exigência de um Plano Individual de Atendimento (PIA) para cada criança, o estabelecimento do tempo máximo de dois anos para o acolhimento institucional e a criação do Cadastro Nacional de Crianças e Adolescentes, no qual deve esta relacionado todas as crianças que se encontram em abrigos.

É importante ressaltar, porém, que essas crianças e adolescentes só podem ser afastadas do convívio familiar se houver uma confirmação de ameaça ou violação de seus direitos. Essas situações acontecem principalmente em relação a práticas parentais coercitivas ou de negligência, falta de apoio familiar, problemas na coesão e hierarquia ou violência multigeracional (Siqueira, Abaid, \& Dell'Aglio, 2012). Desta forma, problemas socioeconômicos enfrentados pela família não podem ser considerados motivos para que a criança vá para uma unidade de acolhimento institucional.

O direito à convivência familiar e comunitária é um dos principais direitos das crianças definido pelo ECA, devendo este direito ser protegido pelo Estado. Neste sentido, conforme referido anteriormente, o acolhimento institucional é uma medida excepcional que só deve ser aplicada como último recurso, quando todas as outras medidas de proteção já foram utilizadas. Por isso, as unidades de acolhimento devem se tornar verdadeiros espaços coletivos de cuidado e educação das crianças e adolescentes para que seja realmente um local de desenvolvimento (Rosseti-Ferreira, Serrano, \& Almeida, 2011a).

Apesar da normatização e legislação avançadas no que se refere aos contextos de acolhimento, a realidade brasileira ainda está passando por mudanças. O ECA traz um novo paradigma de Proteção Integral à Criança e ao Adolescente que pressupõe participação da comunidade e trabalho em rede, algo que ainda não se estabeleceu no Brasil. Além disso, a manutenção das desigualdades sociais e da falta de conhecimento ou possibilidades de dirigentes e profissionais dos abrigos dificultam as mudanças (RossetiFerreira et al., 2011a). Uma pesquisa realizada pelo Instituto de Pesquisa Econômica Aplicada (IPEA) em 2004 constatou que existiam cerca de 20 mil crianças em situação de acolhimento institucional para apenas 589 instituições (IPEA, 2004). Este número reflete o fato da maioria dos abrigos ainda não se apresentarem como unidades pequenas, mantendo, muitas vezes, um número exagerado de crianças em situação precária de provisão, contando com poucos adultos que não conseguem dar conta do cuidado de todas as crianças.

Outra questão relacionada aos abrigos é que estes muitas vezes acabam se tornando instituições totais, onde a criança encontra todos os serviços de que necessita e, ao mesmo tempo, está enclausurada (Nery, 2010; Siqueira et al., 2012). Assim, Cavalcante, Magalhães e Pontes (2007) citam diversos autores que identificam como as relações comunitárias que as crianças têm direito não acontecem, colocando os abrigos que funcionam como instituições totais como um fator de risco para o desenvolvimento das mesmas.

Um estudo feito por Serrano (2011) no interior do estado de São Paulo buscou caracterizar as crianças em situação de acolhimento institucional e suas famílias. Uma das primeiras considerações da autora é que "o abrigamento é masculino, negro e pobre" (p. 116), além de não ser provisório. Já em relação à família, ela encontrou que as mães são as principais responsáveis, em famílias de classe baixa e que acabam por não terem poder para decidir sobre a vida de seus filhos perante os órgãos públicos responsáveis. A mesma autora corroborou seus achados com outros estudos nos quais eles confirmam o perfil dessas crianças como de meninos afro descendentes, em situação de vulnerabilidade social e provenientes de famílias pobres.

Em Salvador, a situação das unidades de acolhimento institucional não é muito diferente do que é colocado como comum em todo o Brasil, pois a maioria deles apresenta 
uma capacidade muito maior do que a de 25 crianças no máximo, com uma média de 40 crianças como limite, dados encontrados a partir de uma relação de unidades em Salvador fornecida pelo Ministério Público, em 2012. Alguns deles, porém, muitas vezes abrigam mais crianças do que é registrado pelo Ministério. Uma questão que é própria de Salvador, entretanto, é que a grande maioria das instituições desta cidade não é mista, sendo que a mistura dos sexos é importante para que o acolhimento institucional se pareça mais com uma vivência familiar, ajudando também nas relações comunitárias da criança.

A realidade das unidades de acolhimento em contraposição ao que é colocado pelo ECA e pelos outros documentos que vão surgindo ao longo do tempo está relacionada à história dessas instituições. Os abrigos surgiram, inicialmente, ligados à Igreja, representados pela roda dos expostos, e tinham também como ideal o controle social dos "menores marginalizados", que deveriam, nesses locais, aprenderem princípios morais portugueses e cristãos (Rosseti-Ferreira, Serrano \& Almeida, 2011b). A partir de 1860, os abrigos se tornaram filantrópicos, mas não mudaram de estrutura inicial, mantendo as crianças ainda em situações vulneráveis e buscando controlar e "ensinar valores" a essas crianças (Siqueira \& Dell'Aglio, 2006). Sem qualquer preocupação com o desenvolvimento, a individualidade e os vínculos familiares, o principal objetivo dos abrigos nessa época era oferecer apenas o mínimo de alimentação, moradia e escolaridade para as crianças institucionalizadas (Siqueira et al., 2012).

Percebe-se por essa parte da história dos abrigos que a forma como as crianças institucionalizadas são tratadas vai depender de como a infância pobre é vista pela sociedade e ao que ela tem ou não acesso, o que é exemplificado pelo uso do termo "menor" no início do século XX para designar crianças pobres, delinquentes e abandonadas, como colocado por Rossetti-Ferreira et al. (2011b). Ainda segundo essas autoras, o Código de Menores em 1923 e o novo código de 1979 surgiram dentro deste propósito de assistência controladora. O primeiro herdou da ação policial as formas de classificação e intervenção dos menores e o segundo deu total poder aos juízes para decidir sobre o destino dessas crianças, sendo que jovens infratores e abandonados eram colocados nos mesmos espaços fechados que funcionavam como instituições totais, não permitindo nenhuma autonomia às crianças.

Foi a partir da nova Constituição de 1988 e da implementação do ECA que o Estado passou a se responsabilizar pelas crianças abrigadas e, assim, a forma de organização desses contextos começou a passar por mudanças (Siqueira \& Dell'Aglio, 2006). No entanto, essa é uma transição que acontece de forma muito lenta e, por isso, muitas instituições apresentam ainda os modelos antigos de abrigos, ou misturam os novos parâmetros com práticas antigas. Desta forma, o acolhimento institucional se torna não apenas um fator de proteção para as crianças abrigadas, mas também é, simultaneamente, um fator de risco.

Esta situação ocorre pois, por um lado, o abrigo possibilita a saída de um contexto de violação de direitos da criança, mas, por outro lado, provoca um aumento dos riscos ao desenvolvimento da criança ao não cumprir o que está estabelecido por lei, se tornando ele mesmo um contexto de vulnerabilidade social. Nesse sentido, a criança abrigada tem muitos dos seus direitos garantidos enquanto outros podem ser diariamente descumpridos.

Diversos são os fatores que podem tornar os abrigos um local de risco ou de proteção para as crianças. Para alguns autores, como Rizzini e Rizzini (2004), o abrigo pode ser um local de proteção a partir do momento que retira as crianças de contextos em que elas estavam vulneráveis à ameaça ou violação de quaisquer dos seus direitos. Apesar de todos os "problemas" que o acolhimento institucional possa causar nas crianças, como diminuição da qualidade da inteligência e da autonomia (Siqueira \& Dell'Aglio, 2006), muitas crianças abrigadas apresentam aspectos positivos da vivência nesses espaços, o que indica que muitas situações que acontecem nos abrigos podem ser favoráveis às crianças (Garzella \& Serrano, 2011; Silva \& Magalhães, 2011; Rosseti-Ferreira, Serrano \& Costa, 2011).

As instituições de acolhimento também podem se tornar contextos de risco para as crianças ao influírem de forma negativa em seu desenvolvimento, através da interação escassa dos adultos com essas crianças, gerando situações de pouco estímulo e falta de vínculos. Entretanto, essa concepção de que a falta de estímulos nos abrigos se caracteriza certamente em um risco para o desenvolvimento já foi refutada por diversas pesquisas que provaram a capacidade das crianças de estabelecerem vínculos entre si (Alexandre \& Vieira, 2004) e de readquirirem um desenvolvimento normal para sua faixa etária quando voltavam a um contexto familiar (Cavalcante et al., 2007). Outra questão importante é que a avaliação das crianças abrigadas acontece a partir de modelos de crianças que vivem em famílias nucleares, considerando-se a quebra do vínculo familiar como um risco em si, mas a análise de crianças abrigadas deve ser diferenciada, observando vínculos formados com outras pessoas do abrigo como fator de desenvolvimento (Ayres \& Coutinho, 2010).

Assim, surge uma terceira ideia relacionada ao abrigo ser um contexto de desenvolvimento da criança, pois, apesar de ser uma situação diferenciada, a criança desenvolve nos abrigos habilidades, competências, personalidade e sociabilidade, mesmo que diferenciados das 
mesmas características de crianças com desenvolvimento considerado normal (Cavalcante et al., 2007). Os abrigos, diferentemente do que se pensa no senso comum e do que muitos teóricos colocam, podem sim atender às necessidades das crianças que ali estão, mesmo que de forma diferenciada do modelo de família nuclear afetuosa, o que não impede que o desenvolvimento dessas crianças aconteça (RossetiFerreira, Serrano \& Costa, 2011). Desta forma, a situação de acolhimento institucional pode apresentar condições reais (mínimas ou não) para que as crianças se relacionem com o ambiente e se desenvolvam, levando em consideração que elas são ativas nesse processo.

Apesar das diversas ideias sobre abrigos, atualmente parece existir um consenso de que o abrigo ser um local de proteção ou de risco é uma questão multifatorial (Siqueira \& Dell'Aglio, 2006) e que, mesmo que o acolhimento institucional possibilite diversas situações de risco, apenas a intensidade, a qualidade e a natureza dessas situações poderiam dizer em que sentido o abrigo se torna um local hostil para o desenvolvimento das crianças abrigadas (Cavalcante et al., 2007), o que irá variar de instituição pra instituição.

Em relação às pesquisas feitas sobre crianças em situação de acolhimento institucional, pode-se dizer que estas são poucas no Brasil, e menos ainda são aquelas que veem essa situação sob a ótica das próprias crianças abrigadas. Uma pesquisa na área de enfermagem, feita por Zem-Marcarenhas e Dupas (2001), visava a conhecer a experiência de crianças em situação de abrigamento. Participaram do estudo crianças de 7 a 13 anos de uma instituição filantrópica no interior de São Paulo, e a coleta de dados se deu por atividades em grupo e entrevistas individuais. As crianças mostraram que, em geral, vivem uma situação conflituosa, pois, ao mesmo tempo que a instituição lhes parece importante por lhes prover os recursos necessários à sobrevivência, também é aquela que retira a criança da vida familiar, para onde muitas desejam voltar.

Já Alexandre e Vieira (2004) pesquisaram o apego entre 14 crianças de 3 a 9 anos institucionalizadas em Santa Catarina, utilizando-se de métodos como observação do sujeito-focal e técnica de registro de comportamento ("amostragem de tempo"), além da observação em grupos durante um curto espaço de tempo ("estudo transversal"). Foram encontradas relações de apegos entre as crianças similares às da díade mãe-filho, como colocado por Bowlby (1984, citado em Alexandre \& Vieira, 2004), especialmente o apego entre irmãos e os vínculos presentes no contexto de brincadeira. $\mathrm{O}$ vínculo entre as crianças se torna, então, um dos fatores de proteção dentro do abrigo.

Há, porém, o Grupo de Investigação sobre Abrigamento, Acolhimento Familiar e Adoção (GIAAA) da USP cujas pesquisas tinham como objetivo conhecer a perspectiva das crianças sobre o acolhimento. Essas pesquisas foram realizadas em abrigos do interior de São Paulo com crianças em idade de 6 a 12 anos, algumas vezes também com os funcionários dos abrigos, e utilizando de metodologias participativas diferenciadas com as crianças, como entrevistas, desenhos, produção de fotos, entre outras.

Os principais achados desta pesquisa envolvem temas como as redes sociais das crianças, que é composta principalmente por pessoas do abrigo, poucas pessoas da família e menos pessoas ainda de outros contextos, como a escola, além dos irmãos serem muito citados, porém pouco procurados pelas próprias crianças para diversas funções dentro do abrigo, dados estes que levaram as autoras a concluírem que a manutenção dos vínculos familiares e comunitários, principalmente dos grupos de irmãos, deve ser prioridade no trabalho dos abrigos (Almeida, Maehara \& Rosseti-Ferreira, 2011). Em outra pesquisa, as crianças também mostraram que poderiam assumir a autoria do que faziam, construindo ativamente significados e percepções do abrigo, que o mostravam como um local de desenvolvimento ao mesmo tempo que explicitavam seus principais problemas (Garzella \& Serrano, 2011).

Silva \& Magalhães (2011) afirmam que uma criança adotada trouxe vivências predominantemente negativas da situação de acolhimento institucional, mas também conseguiu construir significados positivos dessa situação. Apesar disso, os momentos "ruins" foram muito relatados e mostraram algumas concepções sobre a condição de "criança acolhida", como uma criança que não tem voz nem expressão, inadequada até que esteja em ambiente familiar. Essa concepção negativa da criança em situação de acolhimento institucional aparece ainda em outra pesquisa de Buffa e Teixeira (2011) que mostram o quanto essas crianças ainda sofrem preconceitos nas escolas que frequentam e o pouco que as unidades de acolhimento fazem para desconstruir esses preconceitos.

\section{Método}

\section{Contexto}

Para a escolha dos locais onde a pesquisa ocorreria, foi realizado um levantamento dos abrigos da cidade de Salvador e selecionados aqueles que possuíam crianças na faixa etária prevista ( 9 a 12 anos) para a pesquisa em quantidade relevante e que estavam dispostos a receber as pesquisadoras por determinado período. Assim, a pesquisa foi realizada em dois abrigos de Salvador, ambos de caráter misto, localizados em bairros de fácil acesso. As atividades foram realizadas em locais de convivência comum das crianças. 


\section{Participantes}

Participaram da pesquisa 14 crianças de 8 a 12 anos, sendo que 3 meninas eram do primeiro abrigo e as outras 7 meninas e 4 meninos estavam no segundo abrigo ${ }^{1}$. É importante ressaltar que todas as crianças eram negras e que pelo menos 5 delas, apesar de frequentarem a escola, não sabiam ler ou escrever. As crianças foram selecionadas a partir de dois critérios apenas: idade e ter pelo menos uma tarde livre, pois as atividades foram realizadas neste turno.

\section{Procedimentos}

Um dos importantes diferenciais da presente pesquisa é a utilização de metodologias participativas, que partem da premissa de que as crianças são sujeito de direitos, devendo, ter um papel ativo na realização de pesquisas que têm como objeto de estudo seus modos de vida e contextos de desenvolvimento. As metodologias participativas, tal como adotadas na presente investigação, pressupõem que o adulto-pesquisador é responsável por delimitar o tema de investigação e de oferecer propostas que facilitem a participação das crianças, que podem de fato alterar ou redefinir as etapas metodológicas sugeridas pelo pesquisador.

A primeira etapa consistiu na identificação dos abrigos e no estabelecimento dos protocolos de cooperação institucional, que se deu, no primeiro abrigo, através da assistente social e, no segundo, através da psicóloga. Após estabelecido o acordo com as instituições, as pesquisadoras convidaram as crianças a participarem da pesquisa através de um Termo de Assentimento, que contava com informações sobre a pesquisa e seus objetivos para que as crianças tivessem conhecimento do que estariam participando, além de enfatizar a liberdade das crianças de deixarem de participar quando quisessem, permitindo às mesmas escolherem participar ou não da pesquisa e assinarem o papel confirmando sua escolha. A utilização de um termo de assentimento acessível e adaptado ao nível de compreensão das crianças é a primeira questão a ser acautelada pelos pesquisadores que desenvolvem investigações com esse público.

No primeiro abrigo foram realizados dois encontros com as crianças. No primeiro, foi apresentado um vídeo produzido por adolescentes da favela da Rocinha no Rio de Janeiro sobre o ECA (http://www.youtube.com/ watch? $\mathrm{v}=\mathrm{tMuBJbs} 5 \mathrm{~T} 1 \mathrm{M}$ ) que depois foi discutido com as crianças. Por fim, foi realizada uma entrevista semiestruturada sobre direitos com cada uma das 3 meninas, entrevistas estas que foram gravadas e posteriormente transcritas para análise. Essa entrevista continha perguntas sobre conhecimentos gerais de direitos das crianças, 1 Os nomes citados são fictícios, como forma de proteger a identidade dos participantes. momentos em que elas consideravam haver garantia ou violação desses direitos, posicionamentos em relação à violação dos próprios direitos e sobre a diferença entre direitos e deveres, buscando, assim, conhecer não apenas o quanto elas sabiam sobre direitos, mas também suas opiniões em relação ao tema.

No segundo encontro do primeiro abrigo, foi realizado um jogo que consistia em seis potes. Cada pote representava uma pergunta sobre o quanto as crianças eram ouvidas em situações relacionadas ao abrigo, como sobre a entrada e a saída no abrigo, ou se gostavam do abrigo. As crianças tinham que responder colocando bolas de gude nos potes, sendo que 3 bolas representava "muito", 2 "mais ou menos" e 1 "pouco ou nada", já que as crianças não poderiam deixar de colocar bolas de gude, ou seja, não havia a opção de ter 0 . Depois que as crianças colocavam as bolas de gude, era solicitado que as mesmas justificassem suas respostas. Essa atividade foi elaborada a partir de uma adaptação da "atividade dos vasos e dos feijões" utilizada por O'Kane (2005). A autora afirma que todas as estratégias que possibilitem a redução da relação desigual de poder e que sejam interessantes para as crianças favorecem a coleta de dados com este grupo etário, uma vez que as crianças sentem-se mais confortáveis para expor informações sobre seus modos de vida e cotidiano.

Já no segundo abrigo foram realizados quatro encontros semanais com as crianças e em cada encontro houve uma atividade. No primeiro deles, foi apresentado o mesmo vídeo citado acima para as crianças. Ainda neste encontro, foi proposto que elas construíssem cartazes sobre os direitos das crianças. No segundo encontro, realizamos um jogo produzido pelo grupo de pesquisa, um tabuleiro gigante feito de papel metro dividido em casas com um caminho a ser percorrido até a chegada. Cada casa continha uma pergunta sobre direitos das crianças que eles teriam que responder para permanecer na casa ou andar mais algumas casas. Não haviam respostas certas ou erradas, pois o objetivo era saber exatamente o que elas responderiam, o que fazia com que eles sempre conseguissem os objetivos de cada casa. Já no terceiro e quarto encontros, foram realizadas as entrevistas semiestruturadas em duplas e trios e o jogo dos potinhos de forma individual, em cada encontro respectivamente. As diferenças das estratégias metodológicas utilizadas devemse às diferenças dos contextos institucionais e do número de crianças existentes em cada um deles, considerando que o número reduzido de participantes na primeira unidade de acolhimento dificultava a realização de atividades que exigiam a participação de um maior número de crianças, como era o caso do jogo de tabuleiro.

Outra estratégia metodológica utilizada em ambas unidades de acolhimento foi a produção de diários sobre os direitos. A atividade consistia em entregar para cada criança 
um caderno em branco, junto com uma carta explicativa, em que era solicitado que as crianças produzissem um diário, no qual deveriam se apresentar e, depois, escrever diariamente sobre situações de garantia e violação de direitos em suas próprias vidas, ou de outras pessoas que elas presenciassem. Além da carta, as instruções eram passadas verbalmente para evitar a exclusão daqueles que por acaso não soubessem ler e escrever com fluência. As crianças foram incentivadas a decorar e ilustrar os diários como forma de expressar suas impressões e concepções sobre os direitos através de formas de expressão mais distantes da linguagem. Os diários foram recolhidos após uma semana da entrega no primeiro abrigo e após duas semanas no segundo com a promessa que de eles seriam devolvidos em breve, após as pesquisadoras terem feito a digitalização do material produzido.

Após a coleta de dados, o objetivo era que houvesse uma análise preliminar que seria apresentada às crianças em um momento de devolução de uma forma que elas pudessem entender, para que elas validassem as conclusões tiradas pelas pesquisadoras. A devolutiva, porém, acabou tendo um caráter maior de finalização da pesquisa do que de validação das análises, já que não foi possível colocar todas as conclusões tiradas pelas pesquisadoras para as crianças.

\section{Resultados e Discussão}

Caso esta pesquisa tivesse se restringido às entrevistas, o resultado obtido teria demonstrado apenas a confusão que as crianças em situação de acolhimento institucional fazem entre o que são direitos, quais são e a relação que há entre direitos e deveres. Inicialmente, algumas das crianças atestaram não possuir qualquer conhecimento sobre direitos das crianças e outras falavam que sabiam, conheciam o ECA, mas não conseguiam explicar e/ou exemplificar o conteúdo do mesmo. No entanto, ao longo da coleta de dados e a partir das outras estratégias metodológicas foi possível averiguar melhor a forma como estas crianças concebem e vivenciam os seus direitos e/ou a violação dos mesmos.

De forma geral, foi possível verificar que as crianças demonstram ter um conhecimento básico sobre os principais direitos da criança, como educação, brincar, lazer e alimentação, tais como previstos na legislação, sendo destacados os direitos de provisão. Resultados similares foram encontrados por Fernandes (2009) e Santos e Chaves (2010), porém os dados encontrados não corroboram as pesquisas de Ruck et al., (1998) e Haydon (2008), nas quais as crianças falaram mais sobre direitos de autonomia e de serem ouvidas. Essa diferença deve se justificar, porém, pelos países onde essas pesquisas foram realizadas, onde, provavelmente, os direitos de provisão já são assegurados para as crianças e, assim, os direitos de participação são mais enfatizados, já que ainda faltantes.

As crianças da presente pesquisa, no entanto, parecem incluir no rol de direitos a questão da obediência aos adultos e suas regras e do respeito, principalmente com professores e parentes. A dificuldade em diferenciar direitos e deveres aparecia principalmente quando se perguntava na entrevista sobre a relação entre estes dois conceitos, já que muitas não sabiam diferenciá-los e algumas até trocavam o que elas diziam que eram direitos com o que elas consideravam deveres. Algumas das crianças, porém, conseguiram manter a ideia que tinham de direitos, mas colocaram os deveres como uma obrigação de "ser alguém na vida" ou de ajudar com atividades domésticas. Vale ressaltar que esta palavra trouxe grandes problemas por conta de, na cultura baiana, "deveres" ser o termo utilizado para tarefas escolares, o que fez com que algumas crianças falassem de deveres nesses termos.

Ao se questionar aos participantes se todas as crianças sabiam dos seus direitos, metade delas disse que sim e a outra metade disse que não, mas muitas das que responderam não disseram que era porque as crianças pequenas ainda não sabiam. É interessante perceber então o quanto elas se veem conhecedoras dos próprios direitos, mesmo que, na realidade, esse conhecimento seja muito escasso. Algumas das crianças que responderam que nem todos sabem seus direitos disseram também que, se as crianças soubessem, a vida delas seria melhor nos estudos, nas brincadeiras etc., o que pode indicar que eles relacionam o conhecimento dos direitos a uma melhoria direta da situação das crianças, sem perceber que essa melhoria tem que envolver outras pessoas, ou melhor, toda a sociedade.

Outra questão pertinente foi sobre os lugares em que as crianças vivenciavam direitos, pois as duas principais respostas foram "em casa" e "na rua". Assim, mesmo que eles tenham saído de casa provavelmente por conta de uma violação de direitos, elas ainda consideram a casa como um local de garantia de direitos mais do que o abrigo. A questão da rua como local de direitos também é importante, já que, em outras atividades, como no jogo de tabuleiro e no jogo dos potes, as crianças trazem a rua como um local ruim, onde elas estariam se não estivessem no abrigo e onde vivem as crianças que não têm direitos. Assim, a rua representa uma dualidade entre um local que pode ser, ao mesmo tempo, aquele onde as crianças têm seus direitos violados ou para onde elas podem ir quando elas não vivenciam seus direitos em casa, fazendo com que, na rua, eles sejam garantidos.

É válido destacar que não se pode generalizar os dados para todas as crianças em situação de acolhimento institucional, pois suas respostas variam de acordo com as especificidades da sua história de vida e de abrigamento. $\mathrm{O}$ importante é perceber o quanto esse conceito e a relação dos 
direitos das crianças parecem tão distantes daquele trazidos pelo ECA, não apenas porque muitos não correspondem e alguns importantes, como o direito de participação, são esquecidos, mas também porque o que eles trazem correspondem aos direitos que eles possuem na realidade, isso quando os conseguem e não apenas os idealizam. Desta forma, o pouco ou nenhum contato com o estatuto é comprovado não apenas no desconhecimento das crianças, mas no fato deste desconhecimento corresponder a uma realidade faltante de direitos.

A confusão com o conceito de direitos se estende a como elas se percebem, e a outras crianças, como sujeitos de direitos. Inicialmente, todos os participantes relataram acreditar que as crianças possuem direitos. Ao longo da coleta de dados e da realização de outras atividades, porém, as crianças apresentaram diversas condições e incertezas em relação à garantia desses direitos, como analisado a seguir.

Em relação ao por que das crianças possuírem direitos, alguns participantes colocaram que os direitos seriam necessários para fazer as crianças obedecerem (às mães, às "tias"), ou como se as crianças só pudessem ter direitos se obedecessem aos adultos. Esta ideia aparece também quando as crianças dizem o que podem fazer para que seus direitos sejam garantidos, ou seja, que precisam obedecer os adultos ou ajudar em atividades (principalmente domésticas) para terem seus direitos cumpridos. Outra fala comum das crianças em diversos momentos foi a frase de efeito que "se as crianças quiserem ser respeitadas, devem ter respeito pelos outros", o que pode significar que elas têm que agir de determinada forma merecedora (especialmente aos olhos dos adultos) para possuírem os direitos. Colocar condições, principalmente morais ou comportamentais, para que as crianças tenham seus direitos garantidos também foi algo encontrado por Souza (2008) e representa a falta de conhecimento dos participantes em relação aos direitos serem próprios das crianças independente de ações que elas venham a tomar. Ou seja, as crianças, apesar de garantirem que possuem direitos, acabam não se considerando sujeitos de direitos de forma completa, pois mostraram acreditar que seus direitos não estão garantidos e assegurados a priori.

Duas crianças, porém, já trouxeram como justificativa para as crianças terem direitos a necessidade de proteção que as mesmas têm por viverem em um mundo onde elas podem ser maltratadas muito facilmente, como coloca uma das crianças na entrevista: "Do fato de estar sendo muitas crianças assassinadas, serem estupradas, serem espancadas, não ter moradia" (Patrícia - 11 anos). Assim, essas participantes trazem o quanto é importante os direitos para garantir que crianças que estão expostas a vulnerabilidades tenham um mínimo de condições para seu desenvolvimento saudável. São ideias bastante contrárias às trazidas pelas outras crianças anteriormente, mas que podem significar um processo lento de mudança em relação à percepção das crianças que elas não são as únicas e totais responsáveis pelos problemas que acontecem com elas.

Também, quando perguntadas na entrevista sobre o que fariam ou o que outras crianças que conhecem fazem quando seus direitos são violados, os participantes responderam com pequenas ações ou até mesmo a impossibilidade de agir. Assim, ficar triste, chateado, chorar, fazer alguma traquinagem ou fugir, ir pra rua, foram respostas que apareceram quando as crianças falavam de si mesmas e de outras crianças que conheciam, mas no segundo caso elas trouxeram também a violência física e verbal como uma das principais formas de reagir à violação de direitos. Em poucos momentos a procura de responsáveis (pais, dona do abrigo) ou da polícia surgiu como uma das possibilidades para se resolver esses conflitos ou para garantir que os direitos fossem cumpridos, principalmente porque nem sempre são efetivas, pois esta procura não é para as crianças garantia de que o problema será resolvido ou de que seu direito será assegurado. Ou seja, mesmo que acreditem que possuem direitos, as crianças pensam que não podem fazer nada para garanti-los e, se puderem fazer algo, tem que ser por elas mesmas, já que pedir ajuda ou apoio dificilmente entra como uma possibilidade plausível e com certeza de êxito.

É importante ressaltar, porém, o grande conhecimento que as crianças mostraram em relação a situações de violação de direitos, em detrimento ao conhecimento que elas mostraram sobre a garantia dos mesmos. Quando perguntadas na entrevista sobre os momentos em que os direitos das crianças são respeitados, e em outras atividades, as respostas eram bem simplórias e gerais. Já quando era pedido que falassem da violação de direitos, as crianças conheciam diversas formas e histórias relacionadas principalmente com maus tratos maternos (bater, xingar etc.), crianças na rua brigando, usando drogas e crianças sem escola.

Esse conhecimento se estende à comparação entre as características de uma criança que tem direitos garantidos e de uma que tem os direitos violados que aconteceu durante o jogo de tabuleiro. Primeiramente, nos dois casos eles utilizaram uma das meninas que participaram da pesquisa como exemplo de criança que tem seus direitos garantidos, porque ela frequenta o abrigo, mas mora em casa e, como as crianças disseram, é estudiosa, inteligente, "tem os direitos dela". Ou seja, ela era o oposto de uma criança que tem seus direitos violados, que são as próprias crianças do abrigo, porque, segundo elas: "não pode fazer a comida que a gente quer, não pode comprar o que a gente quer, porque às vezes é caro, não pode sair pra rua, não pode sair sozinha, não pode dormir onde a gente quer [...]" (Luana - 10 anos).

O conhecimento sobre violação de direitos aparece 
principalmente no jogo de tabuleiro feito com as crianças do segundo abrigo, no qual elas se mostraram hábeis na hora de contar histórias sobre a cor da pele e a religião terem sido motivo para a violação de direitos de uma criança, colocando as crianças da história como excluídas e inferiorizadas por serem negras ou por serem do candomblé. A questão negra também aparece em outros momentos de conversas informais, principalmente relacionada aos cabelos, com as crianças muitas vezes enfatizando o quanto os cabelos delas são "ruins" e o quanto os cabelos das pesquisadoras são lisos. As crianças também souberam falar bem sobre violação de direitos na hora de falar de personagens de novela que não respeitavam os direitos de crianças.

É interessante observar então o quanto isso simboliza a situação de vulnerabilidade em que se encontram, pois muitas das situações de violação contadas representam aquilo pelo o que elas ou crianças que elas conhecem passaram. São situações que elas vivem cotidianamente e, por isso, representam a vida delas, uma vida baseada em violação de direitos. Soma-se a essa questão o pouco conhecimento que elas apresentam sobre o que podem fazer para que seus direitos não sejam violados, o que ajuda na manutenção dessa situação.

Em relação ao contexto, primeiramente tentou-se entender as situações em que as crianças tinham ou não os direitos de participação garantidos no abrigo. A partir disso, podemos perceber que elas consideram que são mais ouvidas sobre o que farão quando saírem do abrigo do que sobre quando foram encaminhadas para o mesmo, já que muitas reclamam que nem mesmo sabiam por que estavam indo, mas acham que serão escutadas quando forem decidir pra onde elas vão depois do abrigo.

Outros discursos já foram mais variados. Quando perguntadas no jogo dos potes sobre se elas são ouvidas quanto às coisas que querem fazer no abrigo, a maioria disse que sim, mas muitas falaram que não, que as mães sociais não deixavam eles fazerem coisas fora dos horários estipulados, o que é uma característica institucional dos abrigos. Também variaram nas respostas sobre gostarem ou não do abrigo, mas com a principal resposta sendo "mais ou menos", já que, em geral, era melhor estar na família, mas era pior estar na rua. Por isso, também, muitas crianças responderam que era o melhor para elas estar no abrigo naquele momento. Por fim, foi perguntado às crianças sobre o contato delas com a família e a maioria disse que estavam satisfeitas até com parentes que apenas telefonavam, mas algumas crianças falaram não ter nenhum contato com familiares.

Entretanto, mesmo que as crianças digam gostar dos abrigos, uma situação interessante aconteceu no segundo abrigo. Em uma das visitas, as crianças mostraram para as pesquisadoras a versão da música de uma novela que estava passando no momento da coleta de dados, substituindo algumas partes da letra pelo nome da dona do abrigo:

\author{
[...] Queria ver tia Lívia aqui no meu lugar \\ Eu ia rir de me acabar \\ Queria ver tia Lívia aqui no meu lugar \\ Tirando a mesa do jantar [...] \\ [...] A dona do abrigo, \\ A nojenta, a entojada, \\ Só sabe explorar/reclamar, não vale nada.
}

Assim, elas enfatizam o quanto no abrigo não são escutadas e, em geral, só recebem ordens para obedecer, o que explica um pouco o porque delas relacionarem tanto os direitos à obediência e ao respeito. Entretanto, é algo que as crianças não gostam, possivelmente porque vem de cima e a dona do abrigo realmente não sabe o que é estar no lugar delas, ou seja, não procura escutá-las e saber também o que elas acham.

É importante ver então como um local onde os direitos das crianças deveriam ser garantidos ainda tem dificuldades para o fazer, não apenas por questões de dinâmica institucional ou porque as crianças ainda não são muito ouvidas nos processos de abrigamento, mas também por causa da tendência a se desconsiderar a voz da criança e por conta dos parentes muitas vezes não trabalharem juntos com esses abrigos para que as crianças mantenham sua convivência familiar e comunitária. Por outro lado, ficou claro que os abrigos ainda mantêm certas tendências institucionais, principalmente quando uma das crianças colocou em uma conversa informal que a dona do abrigo nunca as levou para passear em qualquer lugar, ou quando as escolas estão dentro das estruturas do abrigo. Assim, o contexto contribui para que as crianças conheçam mais sobre a violação de direitos, pois passam por isso a todo tempo.

Os resultados obtidos nesse estudo são corroborados pelos encontrados por Fernandes (2009) no seu estudo comparativo com crianças de escola pública e de uma instituição de acolhimento em Portugal. Também nesse estudo, as crianças que se encontravam no abrigo mostraram pouco conhecimento e vivência de direitos e mais, se mostraram acostumadas a isso como se fosse algo próprio da vida delas, fazendo com que elas utilizem de estratégias individuais para lidar com essas situações da melhor forma que podem. Assim, as crianças se autorresponsabilizam pelo que passam e acabam não buscando suporte social para que seus direitos sejam garantidos, se satisfazendo com o pouco que conseguem individualmente. 


\section{Considerações Finais}

Através dos dados e da discussão, podemos concluir que o Estatuto da Criança e do Adolescente, apesar de estar alcançando cada vez mais crianças, não chega a todas elas da forma devida. Ao mesmo tempo em que essas crianças possuem alguns dos seus direitos garantidos, pode-se perceber, principalmente em seus discursos com ênfase em situações de violação de direitos, que muitos são descumpridos. Elas também mostraram não saber muitos dos seus direitos e muito menos o que podem fazer para que eles sejam garantidos, fazendo com que aceitem a situação em que estão como se fosse o melhor possível dentro das condições em que vivem.

A confusão mostrada pelas crianças em todas as perguntas sobre direitos e as respostas diferenciadas evidenciam o quanto esse fenômeno de expansão não é uniforme e muito menos explicativo, mas, pelo contrário cria discursos prontos que não significam muito para a criança, já que, no fim das contas, ela sente como se fosse a culpada pelo que passa e a única que pode fazer algo para resolver as situações, o que, na maioria das vezes, não é muito. A auto responsabilização da criança pela garantia dos seus direitos parece ser reflexo de uma concepção hegemônica que prioriza o individualismo e a meritocracia, desconsiderando questões de ordem macrossociais que influenciam e/ou produzem a violência estrutural a que essas crianças, juntamente com suas famílias, são comumente submetidas.

Assim, se faz necessário atentar para o alcance não apenas do conhecimento sobre o estatuto e os direitos que ele traz para essas crianças, mas também de ações efetivas que promovam a garantia desses direitos em um contexto que, em sua base, significa exatamente o respeito aos direitos das crianças, ao tirá-las de situação de vulnerabilidade (e não apenas trocá-las de local de violação de direitos) para que elas possam voltar para famílias que sejam capazes de garantir os direitos das mesmas e, assim, promover um desenvolvimento saudável e pleno dessas crianças, que merecem toda a atenção do Estado, de suas famílias e da sociedade.

\section{Referências}

Alexandre, D. T., \& Vieira, M. L. (2004). Relação de apego entre crianças institucionalizadas que vivem em situação de abrigo. Psicologia em Estudo, 9(2), 207217.

Almeida, I. G. de, Maehara, N. P., \& Rosseti-Ferreira, M. C. (2011). A perspectiva da criança em acolhimento institucional sobre sua rede social: A importância do relacionamento entre irmãos. In M. C. Rosset-Ferreira, S. A. Serrano, \& I. G. Almeida (Orgs.), O acolhimento institucional na perspectiva da criança (pp. 119-172). São Paulo: Hucitec Editora.

Ayres, L. S. M., Coutinho, A. P. C., Sá, D. A., \& Albernaz, T. (2010). Abrigo e abrigados: Construções e desconstruções de um estigma. Estudos e Pesquisas em Psicologia, 2, 420-233.

Buffa, C. G., \& Teixeira, S. C. de P. (2011). Crianças que estão em abrigos e a escola: O universo das corujinhas. In M. C. Rosset-Ferreira, S. A. Serrano, \& I. G. Almeida (Orgs.), O acolhimento institucional na perspectiva da criança (pp. 173-198). São Paulo: Hucitec Editora.

Cavalcante, L. I. C., Magalhães, C. M. C., \& Pontes, F. A. R., (2007). Abrigo para crianças de 0 a 6 anos: Um olhar sobre as diferentes concepções e suas interfaces. Revista Mal-estar e Subjetividade, 7(2), 329-352.

Centro de Apoio Operacional da Infância, Juventude e Educação (2009). Orientações sobre acolhimento institucional. Rondônia: Ministério Público. Recuperado de http:/www.mp.ro.gov.br/c/document library/get_file?p_1_id=75830\&folderId=97798\&nam $\mathrm{e}=$ DLFE-44003.pdf

CNAS - Conselho Nacional de Assistência Social \& CONANDA - Conselho Nacional dos Direitos da Criança e do Adolescente (junho de 2009). Orientações Técnicas para os Serviços de Acolhimento para Crianças e Adolescentes. Brasília. Recuperado de http://www.mds.gov.br/cnas/noticias/cnas-e-conandaorientacoes-tecnicas-servicos-de-acolhimento-paracriancas-e-adolescentes-1

Fernandes, N. (2009). Infância, direitos e participação. Porto: Edições Afrontamento.

Garzella, M. C., \& Serrano, S. A. (2011). O abrigo sob as lentes das crianças: olhares e vozes sobre a convivência na instituição. In M. C. Rosset-Ferreira, S. A. Serrano, \& I. G. Almeida (Orgs.), O acolhimento institucional na perspectiva da criança (pp. 199-234). São Paulo: Hucitec Editora.

Haydon, D. (2008). "Do your promises and tell the truth. treat us with respect": Realizing the rights of children and young people in Northern Ireland. The Journal of the History of Childhood and Youth 1(3), 414-442.

Lei n ${ }^{\circ} 8.069 / 90$ de 13 de julho de 1990. Estatuto da Criança e do Adolescente [ECA].

Lei ${ }^{\circ} 12.010$, de 3 de agosto de 2009. Dispõe sobre adoção; altera as Leis nos 8.069, de 13 de julho de 1990 Estatuto da Criança e do Adolescente, 8.560, de 29 
de dezembro de 1992; revoga dispositivos da Lei no 10.406, de 10 de janeiro de 2002 - Código Civil, e da Consolidação das Leis do Trabalho - CLT, aprovada pelo Decreto-Lei no 5.452, de 1 o de maio de 1943; e dá outras providências. Recuperado de http://www. planalto.gov.br/ccivil_03/_Ato2007-2010/2009/Lei/ L12010.htm

Nery, M. A. (2010). A convivência familiar e comunitária é um direito da criança e do adolescente e uma realidade a ser repensada na escola. Caderno Cedes, 30(81), 187207.

O’Kane, C. (2005). O desenvolvimento de técnicas participativas: Facilitando os pontos de vista das crianças acerca das decisões que as afectam. In P. Christensen, \& A. James (Orgs.), Investigação com crianças: Perspectivas e práticas. Porto: Escola Superior de Educação de Paula Frassinetti.

Rizzini, I., \& Rizzini, I. (2004). A institucionalização de crianças no Brasil: Percurso histórico e desafios do presente. Rio de Janeiro: PUC-Rio.

Rosseti-Ferreira, M. C., Serrano, S. A., \& Almeida, I. G. (2011). Apresentação. In M. C. Rosset-Ferreira, S. A. Serrano, \& I. G. Almeida (Orgs.), O acolhimento institucional na perspectiva da criança (pp. 21-28). São Paulo: Hucitec Editora.

Rosseti-Ferreira, M. C., Serrano, S. A., \& Almeida, I. G. de (2011). A criança e o adolescente como sujeito ativo e de direitos no processo de acolhimento insititucional: Uma longa história ainda inacabada. In M. C. RossetFerreira, S. A. Serrano, \& I. G. Almeida (Orgs.), $O$ acolhimento institucional na perspectiva da criança (pp. 29-59). São Paulo: Hucitec Editora.

Rosseti-Ferreira, M. C., Serrano, S. A., \& Costa, N. R. do A. (2011). Reflexões sobre o desenvolvimento humano e o contexto institucional. In M. C. Rosset-Ferreira, S. A. Serrano, \& I. G. Almeida (Orgs.), $O$ acolhimento institucional na perspectiva da criança (pp. 60-85). São Paulo: Hucitec Editora.

Ruck, M. D., Keating, D. P., Abramovitch, R., \& Koegl, C. J. (1998). Adolescents' and children's knowledge about rights: Some evidence for how young people view rights in their own lives. Journal of Adolescence 21(3), 275-289.

Santos, G. L., \& Chaves, A. M. (2010). Reconhecimento de direitos e significados de infância entre crianças. Revista Semestral da Associação Brasileira de Psicologia Escolar e Educacional, 14(2), 281-290.

Serrano, S. A. (2011). Quem são as crianças institucionalizadas e suas famílias? Refletindo sobre os indicadores de abrigamento em Ribeirão Preto. In M. C. Rosset-Ferreira, S. A. Serrano, \& I. G. Almeida (Orgs.), O acolhimento institucional na perspectiva da criança (pp. 86-118). São Paulo: Hucitec Editora.

Silva, F. L., \& Magalhães, L. de A. (2011).”Assistir Robocop lá é chato!" Conversando com as crianças sobre sua vivência no abrigo institucional. In M. C. Rosset-Ferreira, S. A. Serrano, \& I. G. Almeida (Orgs.), O acolhimento institucional na perspectiva da criança (pp. 235-272). São Paulo: Hucitec Editora.

Siqueira, A. C., Abaid, J. L. W., \& Dell'Aglio, D. D. (2012). Famílias e instituições de acolhimento: Interfaces entre risco e proteção. In L. F. Habigzang, \& S. H. Koller Violência contra crianças e adolescentes: Teoria, pesquisa e prática (pp. 176-189). Porto Alegre: Editora Artmed.

Siqueira, A. C., \& Dell'Aglio, D. D. (2006). O Impacto da institucionalização na infância e na adolescência: uma revisão de literatura. Psicologia \& Sociedade, 18(1), 71-80.

Souza, A. P. L. (2008). A visão de adolescentes de diferentes contextos a respeito de seus próprios direitos. Dissertação de Mestrado, Psicologia. Instituto de Psicologia - Universidade Federal do Rio Grande do Sul, Rio Grande do Sul.

Veiga, F. H. (2001). Students' perceptions of their rights in Portugal. School Psychology International, 22(2), 174189.

Zem-Mascarenhas, S. H., \& Dupas, G. (2001). Conhecendo a experiência de crianças institucionalizadas. Revista da Escola de Enfermagem, 35(4), 413-9.

\section{Endereço para Correspondêcia:}

Juliana Prates Santana

Endereço: Rua Arquimedes Gonçalves, nº 52, Ap. 202, Ed. Maria Clara, Nazaré. Salvador/BA - CEP: 40050-300.

E-mail: julianapsantana@gmail.com

\section{Endereço para Correspondêcia:}

Janaina Rocha Avanzo

Endereço: Instituto de Psicologia - Rua Aristides Novis, $\mathrm{n}^{\circ}$ 2, Estrada de São Lázaro. Salvador/BA - CEP 40210-730.

E-mail: j_rocha_a@hotmail.com 